\title{
Weaning order of vasoactive drugs
}

\author{
Vilto Michels $\mathrm{Jr}^{1^{*}}$ (D) and Daisson José Trevisol ${ }^{1,2}$ \\ See related research by Jeon et al., https://ccforum.biomedcentral.com/articles/10.1186/s13054-018-2034-9
}

In the interesting paper by Jeon et al. [1] the incidence of hypotension while tapering vasopressors in patients recovering from septic shock on concomitant norepinephrine (NE) and vasopressin (AVP) was evaluated. Differing from other studies [2], the authors concluded that the incidence of hypotension was not related to the discontinuation order of the vasopressors, but was related to NE discontinuation. The authors suggested that AVP should be tapered before NE rather than the reverse.

We would like to make some comments on the results.

First, randomization was performed with $\mathrm{NE}$ at $0.3 \mu \mathrm{g} / \mathrm{kg} / \mathrm{min}$; then, tapering started at a rate of $0.1 \mu \mathrm{g} / \mathrm{kg} / \mathrm{min}$ per hour. In the NE group, the average time to the hypotension onset after initiation of NE tapering was $2.5 \mathrm{~h}$, suggesting that hypotension occurred primarily with NE at low-dose ranges. During NE tapering, commonly, taper rates are slower when the lowest dose ranges are reached due to hypotension [3].

Second, regarding NE administration, total NE time was 57.8 (38.9-88) $\mathrm{h}$ and total NE duration before initial tapering was $19.2 \mathrm{~h}$, a very short time for the high hospital mortality found in the study (58.97\%). Additionally, total NE tapering time since randomization just before hypotension was $22 \mathrm{~h}$. However, the length of time between the maximum NE dose of $0.70(0.46-1.20) \mu \mathrm{g} / \mathrm{kg} / \mathrm{min}$ and the randomization dose, which could provide further information on tapering and clinical status before randomization, were not mentioned. The number of NE tapering attempts and the volume required during gradual tapering were also not mentioned.

Third, the administration of other drugs may also have affected the outcome. Many patients received dobutamine and low-dose corticosteroid without following a specific protocol.

Fourth, regarding AVP use, AVP infusion was maintained at $0.03 \mathrm{U} / \mathrm{min}$, below its maximum dose of $0.04 \mathrm{U} / \mathrm{min}$ in septic shock. AVP has an S-shaped dose-response curve. At

\footnotetext{
*Correspondence: michelsjr@uol.com.br

${ }^{1}$ Postgraduate Program in Health Science, University of Southern Santa

Catarina (Unisul), Tubarão, SC, Brazil

Full list of author information is available at the end of the article
}

intermediate doses, it may have a disproportionately high therapeutic effect variation [4]. Perhaps AVP should be kept at its maximum dose for NE tapering. Also, patients in the AVP group had more frequent pneumonia, greater need for mechanical ventilation, and lower PF ratios than in the NE group, which could have stimulated AVP secretion induced by hypoxemia. This finding also suggests that AVP should be maintained at the maximum dose. Hospital mortality was higher in the AVP group than in the NE group $(57.5 \%$ versus $34.2 \%$, respectively; $P=0.039$ ), which suggests that AVP should be tapered after NE.

\section{Abbreviations \\ AVP: Vasopressin; NE: Norepinephrine}

\begin{abstract}
Acknowledgements
Not applicable.

Funding

Not applicable.

Availability of data and materials

Data sharing is not applicable to this article as no datasets were generated or analyzed during the current study.
\end{abstract}

\section{Authors' contributions}

VMJ and DJT analyzed, discussed, and wrote the letter together. Both authors approved the final manuscript.

Ethics approval and consent to participate Not applicable.

Consent for publication

Not applicable.

\section{Competing interests}

The authors declare that they have no competing interests.

\section{Publisher's Note}

Springer Nature remains neutral with regard to jurisdictional claims in published maps and institutional affiliations.

\section{Author details \\ ${ }^{1}$ Postgraduate Program in Health Science, University of Southern Santa Catarina (Unisul), Tubarão, SC, Brazil. ${ }^{2}$ Clinical Research Center of Nossa} Senhora da Conceição Hospital, Tubarão, SC, Brazil. 
Received: 31 July 2018 Accepted: 3 October 2018

Published online: 13 March 2019

\section{References}

1. Jeon K, Song JU, Chung CR, Yang JH, Suh GY. Incidence of hypotension according to the discontinuation order of vasopressors in the management of septic shock: a prospective randomized trial (DOVSS). Crit Care. 2018;22:131-42.

2. Musallam N, Altshuler D, Merchan C, Zakhary B, Aberle C, Papadopoulos J. Evaluating vasopressor discontinuation strategies in patients with septic shock on concomitant norepinephrine and vasopressin infusions. Ann Pharmacother. 2018;52(8):733-9.

3. Arellano DL, Hanneman SK. Vasopressor weaning in patients with septic shock. Crit Care Nurs Clin North Am. 2014;26(3):413-25.

4. Pang CCY, Tabrizchi R. The effects of noradrenaline, B-HT 920,

methoxamine, angiotensin II and vasopressin on mean circulatory filling pressure in conscious rats. Br J Pharmac. 1986;89(2):389-94. 